\title{
The Effect of Salinity Acclimation on the Upper Thermal Tolerance Threshold of the European Green Crab
}

\author{
Muñoz LST ${ }^{1}$, Kelley $\mathrm{AL}^{2 *}$ and De Rivera $\mathrm{CE}^{3}$ \\ ${ }^{1}$ Department of Biology, Portland State University, USA \\ ${ }^{2}$ University of Alaska Fairbanks, USA \\ ${ }^{3}$ Department of Environmental Science \& Management, Portland State University, USA
}

Submission: June 28, 2017; Published: July 28, 2017

*Corresponding author: Kelley AL, Fairbanks, School of Fisheries and Ocean Sciences, University of Alaska Fairbanks, AK 99775-7220, USA, Tel: + (907)-474-2474, Email: alkelley@alaska.edu

\begin{abstract}
Fluctuations in salinity and temperature, among other varying environmental conditions, are stressors in estuaries and may work together to alter the physiological response of organisms that inhabit such environments. Laboratory assessments that investigate how animals respond to multiple environmental stressors can provide an ecological framework for understanding physiological performance across varying conditions. In this study, European green crabs, Carcinus maenas, were collected from Seadrift Lagoon, California, USA $\left(37^{\circ} 54^{\prime} 27.82^{\prime \prime} \mathrm{N}, 122^{\circ} 40^{\prime} 19.56^{\prime \prime} \mathrm{W}\right)$ and were lab-acclimated at three different salinity concentrations typical of many estuaries: 15,25 , and $35 \mathrm{PSU}$ at $12^{\circ} \mathrm{C}\left( \pm 1^{\circ} \mathrm{C}\right)$. After acclimation, crabs from each salinity treatment experienced a temperature ramp of $2{ }^{\circ} \mathrm{C}$ every $30 \mathrm{~min}$ until they reached their critical thermal maxima (CTmax). Crabs held at 15 PSU acclimation treatment died at significantly lower temperatures than those acclimated to 25 PSU, demonstrating that the upper thermal tolerance of $C$. maenas is decreased at lower salinities. Hence, crabs in the northeast Pacific, which are limited to estuarine and brackish waters by marine predators, may be physiologically limited from further expanding their southern range boundary due to the effect of increased temperature on physiological performance. This work took place in March, 2013 and highlights the importance of examining the effect of multiple stressors to understanding what factors may limit or enhance range shifts.
\end{abstract}

Keywords: Carcinus maenas; Multi-stressor; Salinity acclimation; Thermal tolerance; Abiotic resistance; Invasive species

\section{Introduction}

Ecophysiological research has historically focused on altering one abiotic variable at a time to measure the physiological response to that variable. However, examining how multiple stressors affect organisms provides a more holistic view into factors that govern distribution and abundance of species [1-3]. The intersection of fresh and salt water, coupled with thermal fluctuations typical of estuaries can affect physiological performance, leading to geographic distribution limitations of estuarine organisms Sokolova et al. [4]. Additionally, along the west coast of North America, the estuarine distribution of Carcinus maenas has been attributed to predation by a larger, aggressive native crab Hunt \& Yamada [5].

Owing to their broad thermal and salinity tolerance, $C$. maenas has successfully invaded coastal habitats of four continents, including the west coast of North America [6-8]. In addition, $C$. maenas can survive and reproduce in a wide range of salinity concentrations because they are proficient osmoregulators [9]. Nagaraj [6] found that salinity had little to no effect on developmental rates of $C$. maenas; however, zoeae kept in high salinity treatments (25 and 35ppt) had the greatest survival rates at the lowest experimental temperature, $\sim 10{ }^{\circ} \mathrm{C}$ [6]. While these studies are informative, they do not necessarily reflect the dynamic abiotic environment that $C$. maenas inhabits.

In the eastern Pacific, C. maenas is preyed upon by native crabs, limiting their habitat use of the open coast, consequently forcing $C$. maenas to occupy areas with greater temperature and salinity fluctuations [5]. As such, C. maenas populations generally reside in upper estuaries, which are characteristically warmer and less salinated [5]. For C. maenas specifically, exposure to lower salinities leads to increased oxygen demand (i.e. increased anaerobic metabolic rate) as a means to offset the concomitant increase in hemolymph $\mathrm{pH}$, which in turn affects the hemolymph's $\mathrm{O}_{2}$ affinity [10]. The variable salinity concentration of estuaries in conjunction with their often warmer conditions 
[5] may combine to limit the ability of C. maenas to mount robust heat stress response, thus lowering the upper thermal tolerance, despite it being a euryhaline hyperosmotic regulator. Ionic stress combined with heat stress has been investigated in larval C. maenas; however, the effect of variations in salinity concentrations on adult crab upper thermal tolerance has yet to be investigated. To better understand how variations in salinity affect the upper thermal tolerance of adult crabs, animals were acclimated to three different salinity concentrations common to estuaries and then were subject to acute heat stress. Given that $C$. maenas is an osmoregulator, such that decreased salinity increases metabolic demand, we hypothesized that a reduction in salinity would circumvent the ability of $C$. maenas to mount a robust response to heat stress, thus reducing organismal thermotolerance.

\section{Methods}

\section{Sampling, maintenance, and salinity treatments}

Male and female Carcinus maenas were collected from Seadrift Lagoon, Stinson Beach, California, USA in August 2012, and transported to Portland State University, Oregon, USA. The crabs were temperature acclimated at $12{ }^{\circ} \mathrm{C}\left( \pm 1{ }^{\circ} \mathrm{C}\right)$ and 30 PSU for approximately $210 \mathrm{~d}$ prior to the salinity acclimation phase. Three groups were then formed via random selection and acclimated to 15,25 , or 35 PSU, encompassing the salinity conditions where they are typically found ( 10-35 PSU) [11] for 56d. Each salinity-controlled treatment group was held in a separate, self-sustaining, recirculating-water, temperaturecontrolled aquarium table system in artificial sea water (Instant Ocean) treated with $20 \mathrm{~mL}$ of a nitrogen reducer (AmQuel) per approximately 151.42L of water, when nitrogen was high. System salinity was held within \pm 1 PSU of the target salinity concentration for each treatment group by thrice weekly salinity measurements and additions of deionized water as needed to maintain the respective salt concentrations. The crabs were fed a medley of squid, fish, and mussels ad libitum, once per week.

\section{Heat ramping}

Members of the $C$. maenas sample population ( $\mathrm{n}=15$ per treatment) were randomly selected from each salinity treatment and placed in recirculating and continually aerated water bath (Lauda RM6 MGW) filled with aquarium water from their acclimation tank. The bath was then ramped up by $2{ }^{\circ} \mathrm{C}$ every $30 \mathrm{~min}$, beginning from a base temperature of $12{ }^{\circ} \mathrm{C} \pm 1$ ${ }^{\circ} \mathrm{C}$ Kelley et al. [7]. The temperature at which each crab expired was monitored with a Vernier thermometer probe $\left( \pm 0.1^{\circ} \mathrm{C}\right)$ and recorded. Critical thermal maximum (here after CTmax), a standard measure of temperature-related animal death, was determined via a set of criteria verified by physical examination [7]. If the specimen was unresponsive to manipulation and could not right itself, it was held just below the surface of the water and examined for signs of respiration, i.e., water movement via the activity of the scaphognathite Crothers [12]. If cessation of respiration lasted for longer than $30 \mathrm{~s}$, the specimen was considered physiologically deceased and was removed from the water bath. Upon each crab's death, we removed the specimen and recorded its treatment group, sex, temperature at death, and carapace width. Heat ramping continued until all of the experimental animals expired.

\section{Statistics}

To determine that the assumptions of normality and homoschedasticity were not violated, the Kolmogorov-Smirnov Goodness-of-Fit Test $(P=0.57)$ and Bartlett's test for equal variance $(P>0.1)$ were used (Graphpad Prism) prior to analysis. Analysis of Covariance (ANCOVA), followed by Tukey's Multiple Comparison Test were employed to determine whether salinity (fixed) and crab size (continuous covariate) affected the upper thermal tolerance of the crabs (Minitab 17). To further explore the relationship between carapace width (CW) and CTmax, a linear regression was used (Graphpad Prism).

\section{Results}

The three salinity treatments differed in their mean CTmax values (Figure 1, Table 1, ANCOVA, $\mathrm{F}(2,42)=4.16, P=0.02$ ) The mean differences in CTmax between 15 PSU and 25 PSU, 15 PSU and 35 PSU, and 25 PSU and 35 PSU were -2.6, -1.3, and $1.3{ }^{\circ} \mathrm{C}$, respectively. Tukey's Multiple Comparison Test revealed a significant difference between the 15 PSU and the 25 PSU samples: the average CTmax of the 15 PSU sample 32.5 ${ }^{\circ} \mathrm{C} \pm 0.6^{\circ} \mathrm{C}$ ) was significantly lower than that of the 25 PSU sample $\left(35.0^{\circ} \mathrm{C} \pm 0.46^{\circ} \mathrm{C}\right.$, Figure 1$)$. The 35 PSU treatment was intermediate, having an average CTmax of $33.7^{\circ} \mathrm{C} \pm 0.6$, and did not significantly differ from the CTmax values of the other two salinity treatments. CW also significantly affected the upper thermal tolerance threshold, with lower CTmax for larger crabs (Figure 2: $\mathrm{r}^{2}=0.2, \mathrm{y}=-0.1^{*} \mathrm{x}+41$; ANCOVA. $\left.\mathrm{F}(2,41) ; P=0.008\right)$.

Table 1: ANCOVA results salinity as a fixed factor and carapace width (CW) as a covariate.

\begin{tabular}{|c|c|c|c|c|c|}
\hline Source & DF & Adj SS & Adj MS & F-Value & P-Value \\
\hline CW & 1 & 30.42 & 30.4 & 7.71 & 0.008 \\
\hline Salinity & 2 & 32.83 & 16.42 & 4.16 & 0.023 \\
\hline Total & 44 & 243.62 & - & - & - \\
\hline S & r2 (adj) & - & - & - & - \\
\hline 1.99 & $28.77 \%$ & - & - & - \\
\hline
\end{tabular}


Fisheries and Oceanography Open Access Journal

\begin{tabular}{|c|c|c|c|c|c|}
\hline Coefficients & - & - & - & - & - \\
\hline Term & Coef & & SE Coef & T-Value & P-Value \\
\hline Constant & 39.43 & 2.08 & - & 18.93 & $<0.001$ \\
\hline CW & -0.0914 & 0.0329 & - & -2.78 & 0.008 \\
\hline Salinity & - & - & - & -2.6 & - \\
\hline 15 & -1.103 & 0.425 & - & 2.42 & 0.013 \\
\hline 25 & 1.042 & 0.431 & - & 0.02 \\
\hline
\end{tabular}

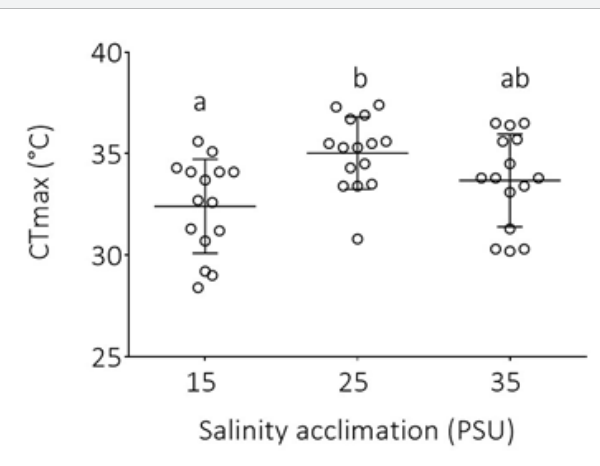

Figure 1: Effect of salinity acclimation on CTmax $\left({ }^{\circ} \mathrm{C}\right)$ of $C$. maenas: lines represent means, and error bars standard deviation ( $n=15$ each salinity acclimation), and different letters represent a significant difference between treatments $(P<0.05)$.

\section{Discussion}

We found that adult crabs that were acclimated to low salinity concentrations showed greater susceptibility to rising temperature. Crabs acclimated to lower salinity had a significantly lower CTmax than crabs acclimated to 25 PSU, supporting our initial hypothesis that lower salinity environments can negatively affect the upper thermal tolerance of adult Carcinus maenas. This finding was in accordance with a study that examined the effect of salinity acclimation on thermotolerance and larval development distribution of larval C. maenas Nagaraj [6]. Similarly, in another study, temperature interacted with salinity, together affecting larval development duration and attachment of the barnacle Balanus trigonus Thiyagarajan et al. [13]. Variations in salinity and temperature significantly modified the development of Nile tilapia, Oreochromis niloticus, but the interaction of the two variables modified development in unpredictable ways, with growth rates peaking at different temperatures as salinity changed Likongwe et al. [14]. A decrease in salinity concentration was also shown to significantly limit the range of temperatures tolerable by the bivalves Mercenaria mercenaria and Crassostrea virginica, for both survival and larval development Davis and Calabrese [15].

Our CTmax data suggest that after acclimation to a low salinity (15 PSU), temperature tolerance decreased significantly, offering an additional abiotic variable that may further limit their distribution. Hence, a large expansion south to warmer waters along the western North American coast seems unlikely.
This observed decrease in temperature tolerance implies that although C. maenas is capable of tolerating low salinities, it is metabolically taxing for them and could synergistically alter their ability to physically cope with thermal stress. Southward expansion of east coast C. maenas populations has been documented to be limited by native crab species found in estuaries De Rivera et al. [16], our data suggest that salinity and temperature in concert with predation together limit southward expansion. Together these multiple stressors may determine the potential for future range expansion of $C$. maenas.

A recent study found a significant relationship between environmental temperature and body size across this population of $C$. maenas, with larger crabs occupying areas of cooler temperatures, a phenomenon known as the temperaturesize rule for ectotherms Kelley et al. [17]. Here, we have shown that larger crabs tend to have a lower overall thermal tolerance threshold than smaller crabs (Figure 2). This study provides further evidence supporting the temperature-size rule in that large crabs that inhabit warmer, hyposaline water are more susceptible to heat stress, such that temperature acts as a selection force against larger body size.

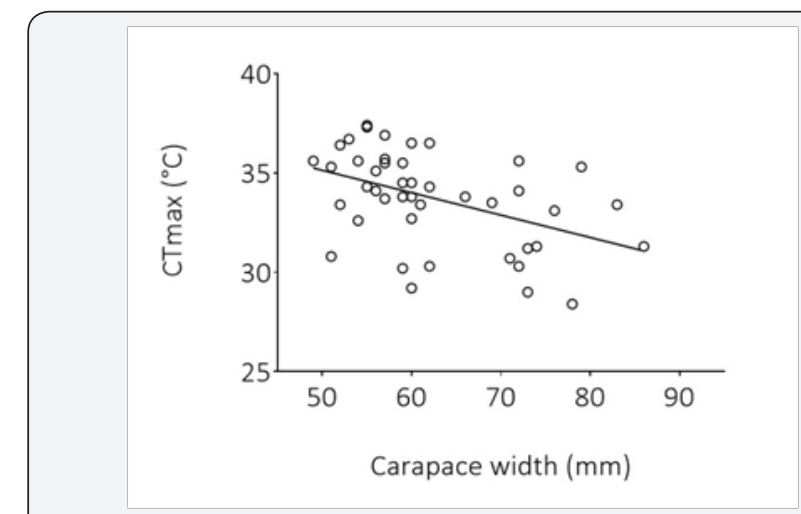

Figure 2: Linear regression of carapace width $(\mathrm{mm})$ and CTmax $\left({ }^{\circ} \mathrm{C}\right), \mathrm{r}^{2}=0.2, y=-0.1^{*} \mathrm{x}+41$

Our study's findings add to the body of literature supporting the conclusion that multiple stressors combine synergistically and may affect geographic range expansion and possibly overall success; however, the exact effects and synergistic relationship differ across species Todgham et al. [18], Crain et al. [1], McBryan et al. [19], Todgham and Stillman [3]. Together these studies, and others, suggest that the interaction between salinity concentration and temperature on aquatic life is not 
purely additive, and that more research is needed on multiple environmental stressors acting in one system, especially to predict the geographic distribution of species as their ranges shift due to climate change or biological invasion. Because of overwhelming evidence of climate change, it is important to consider the implications of inevitable further rise in temperature and changing estuarine salinities on native and non-native marine species in the near future Kelley [20], Sorte et al. [21]. The predicted change in riverine input could alter salinity and temperature along with $\mathrm{pH}$, and could be modeled to understand potential future distributions. Life at low salinity levels and high temperatures becomes increasingly difficult for native and invasive species and can cause northward range expansion of C. maenas Kelley et al. [3], Hunt and Yamada [5]. It is important to understand the many abiotic factors can affect $C$. maenas distribution in order to predict future range expansions and possible ecological and economic effects of a non-native species on native marine animals and delicately balanced ecosystems.

\section{Conclusion}

This study documents that other environmental factors influence the upper thermal tolerance of the invasive Carcinus maenas, the European green crab. Understanding the role that dynamic environments play in regulating the physiological tolerances of invasive organisms is critical to gaining insight regarding the ecology of biological invasions. This research underscores the importance of, and the need to conduct studies that investigate the interplay of multiple environmental stressors on the physiology of non-native species.

\section{Acknowledgment}

We would like to thank Juanes Collazo for her invaluable assistance during the thermal tolerance experiments. Amanda L Kelley was supported by a National Science Foundation Graduate Research Fellowship- award number 220005, a National Science Foundation GK-12 Graduate Fellowship- award number 0948041. Lauren S. Muñoz-Tremblay was supported by award from Portland State University's Louis Stokes Alliance for Minority Participation in Science, Technology, Engineering, and Mathematics; award number HRD-1410465.

\section{References}

1. Crain CM, Kroeker K, Halpern BS (2008) Interactive and cumulative effects of multiple human stressors in marine systems. Ecol Lett 11(12): 1304-1315.

2. Hofmann GE, Todgham AE (2010) Living in the now: Physiological mechanisms to tolerate a rapidly changing environment. Annu Rev Physiol 72: 127-145.

3. Todgham AE, Stillman JH (2013) Physiological responses to shifts in multiple environmental stressors: relevance in a changing world. Integr Comp Biol 53(4): 539-544.

4. Sokolova IM, Frederich M, Bagwe R, Lannig G, Sukhotin AA (2012)
Energy homeostasis as an integrative tool for assessing limits of environmental stress tolerance in aquatic invertebrates. Mar Environ Res 79: 1-15.

5. Hunt CE, Yamada SB (2003) Biotic resistance experienced by an invasive crustacean in a temperate estuary. Biological Invasions 5(12): $33-43$.

6. Nagaraj M (1993) Combined effects of temperature and salinity on the zoeal development of the green crab, Carcinus maenas (Linnaeus, 1758)(Decapoda: Portunidae). Science Marine 57(1): 1-8.

7. Kelley AL, de Rivera CE, Buckley BA (2011) Intraspecific variation in thermotolerance and morphology of the invasive European green crab, Carcinus maenas, on the west coast of North America. Journal of Experimental Marine Biology and Ecology 409: 70-78.

8. Kelley AL, de Rivera CE, Buckley BA (2013) Cold tolerance of the invasive Carcinus maenas in the east Pacific: molecular mechanisms and implications for range expansion in a changing climate. Biological invasions 15(10): 2299-2309.

9. McGaw I, Reiber C, Guadagnoli J (1999) Behavioral physiology of four crab species in low salinity. The Biological Bulletin 196: 163-176.

10. Legeay A, Massabuau JC (2000) Effect of salinity on hypoxia tolerance of resting green crabs, Carcinus maenas, after feeding. Marine Biology 136(3): 387-396.

11. Behrens-Yamada S (2001) Global invader: Oregon Sea Grant, Oregon State University, USA.

12. Crothers JH (1968) The biology of the shore crab, Carcinus maenas (L) 2: The life of the adult crab. Field Studies 2: 579-614.

13. Thiyagarajan V, Harder T, Qian PY (2003) Combined effects of temperature and salinity on larval development and attachment of the subtidal barnacle Balanus trigonus Darwin. Journal of Experimental Marine Biology and Ecology 287: 223-236.

14. Likongwe JS, Stecko TD, Stauffer JR, Carline RF (1996) Combined effects of water temperature and salinity on growth and feed utilization of juvenile Nile tilapia Oreochromis niloticus (Linneaus). Aquaculture 146: 37-46.

15. Davis HC, Calabrese A (1964) Combined effects of temperature and salinity on development of eggs and growth of larvae of M. mercenaria and C. virginica. Fishery Bulletin 63: 643-655.

16. De Rivera CE, Ruiz GM, Hines AH, Jivoff P (2005) Biotic resistance to invasion: native predator limits abundance and distribution of an introduced crab. Ecology 86(12): 3364-3376.

17. Kelley AL, de Rivera CE, Grosholz ED, Ruiz GM, Yamada SB, et al. (2015) Thermogeographic variation in body size of Carcinus maenas, the European green crab. Marine Biology 162(8): 1625-1635.

18. Todgham AE, Schulte PM, Iwama GK (2005) Cross-tolerance in the tidepool sculpin: the role of heat shock proteins. Physiol Biochem Zool 78(2): 133-144.

19. McBryan T, Anttila K, Healy T, Schulte P (2013) Responses to temperature and hypoxia as interacting stressors in fish: implications for adaptation to environmental change. Integr Comp Biol 53(4): 648659.

20. Kelley AL (2014) The role thermal physiology plays in species invasion. Conserv Physiol 2(1): cou045.

21. Sorte CJ, Ibáñez I, Blumenthal DM, Molinari NA, Miller LP, et al. (2013) Poised to prosper? A cross-system comparison of climate change effects on native and non-native species performance. Ecology Letters 16(2): 261-270. 
CC (9) This work is licensed under Creative Commons Attribution 4.0 Licens DOI:_10.19080/OFOAJ.2017.04.555627
Your next submission with Juniper Publishers will reach you the below assets

- Quality Editorial service

- Swift Peer Review

- Reprints availability

- E-prints Service

- Manuscript Podcast for convenient understanding

- Global attainment for your research

- Manuscript accessibility in different formats ( Pdf, E-pub, Full Text, Audio)

- Unceasing customer service

Track the below URL for one-step submission https://juniperpublishers.com/online-submission.php 